Khawla M Awni BDS, MSc (Lec)

\section{Comparison Between Laceback and Tie- back in Sliding Mechanics \\ (An in vitro study)}

\author{
Dept of Pedod, orthod, and Prev Dentistry
}

College of Dentistry, University of Mosul

$$
\begin{aligned}
& \text { الحلاصة }
\end{aligned}
$$

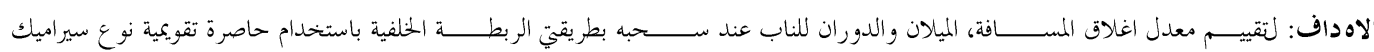

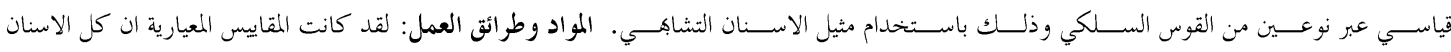

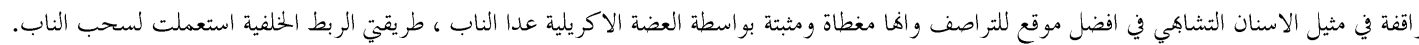

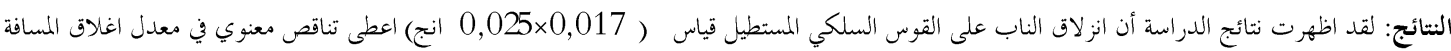

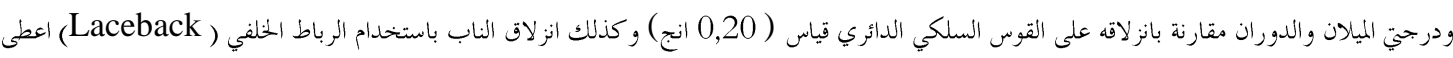

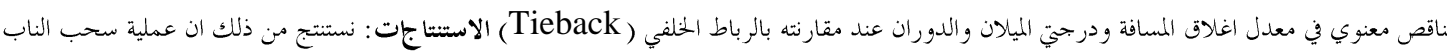

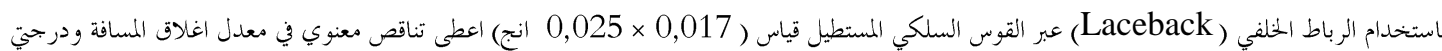

$$
\begin{aligned}
& \text { الميلان والدوران. }
\end{aligned}
$$

\begin{abstract}
Aims: The current study aims to investigate the rate of space closure, tipping and rotation of canine during its retraction by laceback and tieback using standard ceramic brackets along 2 types of archwires using typodont simulation system (Ormco). Materials and Methods: The standardization criteria were all typodont teeth situated in well aligned position, covered and immobilized by the acrylic bite except canine, laceback and tieback were used to slide the canine. Results: The present study showed that when slide the canine on $0.017 \mathrm{x} 0.025$ inch archwire gave rise to significant decrease in the rate of space closure, degree of tipping and rotation as compared when sliding it on 0.020 inch archwire, also sliding the canine using laceback as a method of retraction gave rise to a significant decrease in the rate of space closure, degree of tipping and rotation as compared with tieback. Conclusions: It was concluded that canine retraction using laceback retraction method along $0.017 \times 0.025$ inch archwire gave rise to a significant decrease in the rate of space closure, degree of tipping and rotation.
\end{abstract}

Key Words: Laceback, Tieback, Sliding mechanics.

Awni KM. Comparison Between Laceback and Tieback in Sliding Mechanics (an in vitro study). $A l-$ Rafidain Dent J. 2012; 12(1): 148-152.

Received: 13/10/2010 Sent to Referees: $19 / 10 / 2010$

Accepted for Publication: 4/1/2011

\section{INTRODUCTION}

Sliding mechanics are commonly used orthodontic techniques to close interdental spaces in which the bracketed tooth, in effect, slide along an archwire. ${ }^{(1)}$

Elastic tieback: Using an elastomeric module, of the type used to hold archwires on to bracket, stretched to twice its normal size; this was found to give a force of 50$100 \mathrm{gm}$ if the module was pre-stretched before use. ${ }^{(2,3)}$

Laceback: These are 0.010 or 0.009inch steel ligature in a figure of eight running from the canine to the premolar which hold back the canine crown whilst uprighting occurs and at the same time lightly retracts the canine. ${ }^{(4)}$

The aims of this study were to investigate the rate of space closure, tipping and rotation of canine during its retraction by laceback and tieback methods.

\section{MATERIALS AND METHODS}

The sample of this study consisted of 4 sets of standard ceramic brackets " 0.022 inch" (only lower incisors, canines and second premolars), forty stainless steel archwires divided into 2 types (0.020inch and $0.017 \times 0.025 i n c h)$, twenty laceback and 20 tieback. This study was conducted using typodont model, the brackets were 
fixed on metallic teeth using epoxy steel adhesive which is supplied into two tubes (hardener and resin).Each bracket is positioned in its proper position by the aid of bracket positioning gauge to ensure greater vertical accuracy. ${ }^{(5)}$ This study was conducted using class III typodont wax form, so alignment of the teeth was required to obtain a well aligned tooth. ${ }^{(2,6-8)}$ This was done by placing the archwires in the lower arch that were progressively upgraded through leveling and aligning and finally to $0.019 \times 0.025$ inch stainless steel wire after immersing the typodont in a water bath at $54^{\circ} \mathrm{c}$ for 5 minutes. ${ }^{(2,9)}$ This

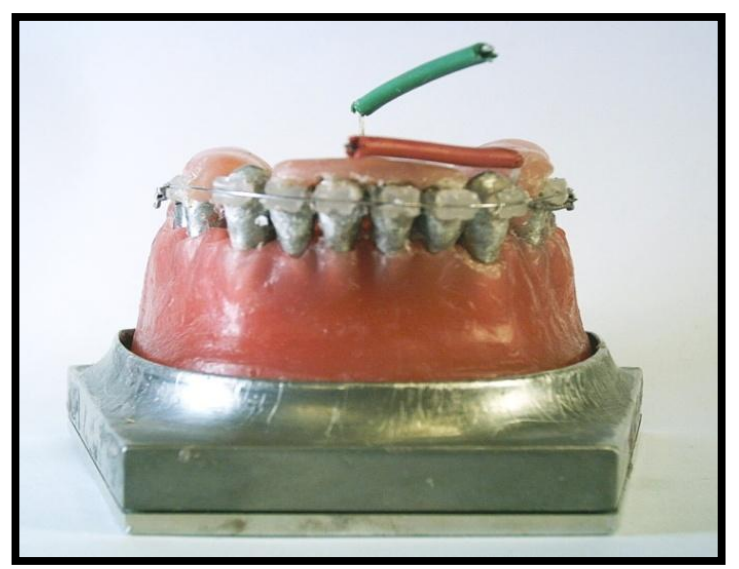

Figure (1): Bite plane extension bar and canine extension bar.

were used, bite plane extension bar is an (L-shape) bar made of stainless steel rectangular wire of size $(0.018 \times 0.022$ inch). The short arm is inserted in a groove which is made in the simulated lingual area of the acrylic bite .This bar emerges upward for $(10 \mathrm{~mm})$ distance then it was bends at right angle to extend facially $(20 \mathrm{~mm})$ in a canine direction making right angle with (canine extension bar) which is an (L-shape) bar made of stainless steel rectangular wire of size $(0.018 \times 0.022 \mathrm{inch})$. The short arm is soldered to the distal aspect of canine by the use of electronic iron soldering device that extend incisally for $(10 \mathrm{~mm})$ distance then it bends at right angle to extend anteriorlly $(20 \mathrm{~mm})$, and $(5 \mathrm{~mm})$ over canine cusp tip. These two bars are used as a guide for determining degree of tipping and rotation of canine following sliding movement ${ }^{(12)} \mathrm{Be}-$ fore starting movement of canine (left canine only) the distance between distal

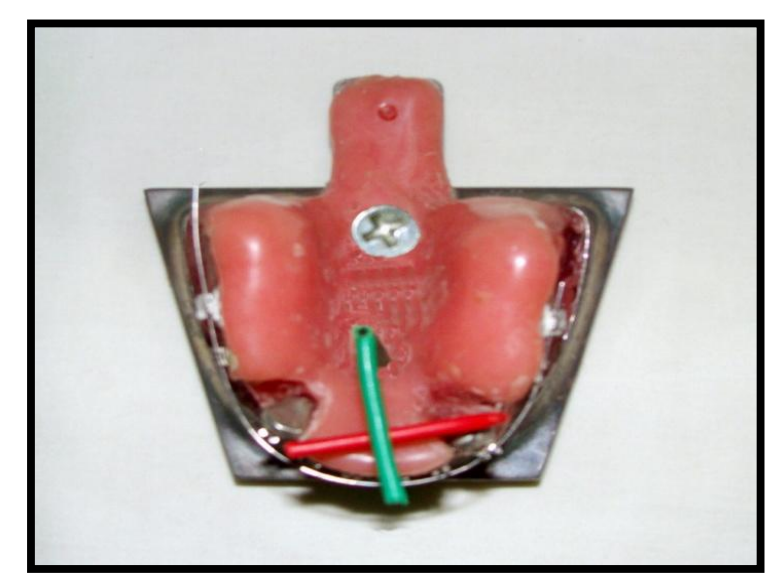

archwire was ligated to the bracket by using elastomeric ligature because the high variability of tying ligatures makes the use of elastic ligatures the most reproducible. ${ }^{(10)}$ An active tieback (distal module), the elastomeric module is attached to the $1^{\text {st }}$ molar hook, a 0.010 ligature is used with one arm beneath the archwire, this makes the active tieback more stable, and helps to keep the ligature wire away from the gingival tissues. ${ }^{(2)}$ Laceback applied from molar hook to the canine bracket. ${ }^{(11)}$ Bite plane extension bar and canine extension bar as showen in Figure (1) 
Table (2): Comparison of the space closure rate, tipping and rotation between two methods of retraction along two types of archwires.

\begin{tabular}{cccccccc}
\hline & & \multicolumn{2}{c}{ Laceback } & \multicolumn{2}{c}{ Tieback } & \multirow{2}{*}{ t-value } & \multirow{2}{*}{$\boldsymbol{p}$-value } \\
\hline Rate of space & $\begin{array}{c}0.017 \times 0.025 \\
\text { inch }\end{array}$ & 1.51 & 0.017 & 2.55 & 0.015 & -138.96 & 0.000 \\
closure & 0.020 inch & 1.62 & 0.016 & 2.50 & 0.14 & -19.50 & 0.000 \\
\hline \multirow{2}{*}{ Tipping } & $\begin{array}{c}0.017 \times 0.025 \\
\text { inch }\end{array}$ & 1.10 & 0.51 & 3.95 & 0.64 & -10.92 & 0.000 \\
& 0.020 inch & 3.0 & 0.33 & 6.00 & 0.66 & -12.72 & 0.000 \\
\hline \multirow{2}{*}{ Rotation } & $\begin{array}{c}0.017 \times 0.025 \\
\text { inch }\end{array}$ & 1.05 & 0.43 & 4.30 & 0.63 & -13.36 & 0.000 \\
& 0.020 inch & 2.00 & 0.33 & 5.00 & 0.66 & -12.72 & 0.000 \\
\hline
\end{tabular}

Rate of space closure measurements in millimeter. Tipping and Rotation measurements in millimeter. Number of each group $=10$. $\mathrm{t}$ - is significant at $p \leq 0.05$.

\section{DISCUSSION}

\section{* Rate of space closure}

1. Arch Wire Shape: In the present study, the rate of space closure with round arch wire was greater than rectangular one. This is in agreement with Frank and Nikolai ${ }^{(17)}$ who cited that the distribution of normal force may be a significant factor, where the round wire makes only point contact with a bracket slot.

2. Methods of Retraction: The present study showed that using tieback show highest mean value for the rate of space closure because it applies a defined force to the arch wire and teeth. ${ }^{(3)}$ In laceback group the amount of canine movement were smaller this can be explained by the force characteristics of laceback ligatures which cause a slight tipping of the canine, the canine's root have enough rebound time to move upright into its correct position as the main arch wire takes effect. ${ }^{(18)}$

\section{*Degree of Tipping and Rotation}

1. Arch wire shape: Rectangular arch wire produces little degree of tipping and rotation, this in agreement with Ziegler and Ingerval, ${ }^{(19)}$ also rectangular wires usually used to achieve three-dimensional controlled tooth movement. ${ }^{(20)}$

2. Methods of retraction: Distopalatal rotation and tipping of the canine was observed because of the relationship between the force application and center of resistance. ${ }^{(11)}$ The laceback group showed lowest degree of tipping and rotation than tie- back group because of the interrupted force of laceback the canine is given enough "rebound time" to upright and rotate distobuccaly into correct position as the main arch wire takes effect. ${ }^{(12)}$ while the tieback group showed highest degree of tipping and rotation because rapid space closure might produce loss of tipping and rotational control adjacent to the extraction site. ${ }^{(21)}$ Also excessive force at the start of treatment leads to tipping and rotation of canine in the extraction spaces. ${ }^{(3)}$

\section{CONCLUSIONS}

1. Laceback ligatures proved to be effective for canine distalization.

2. Sliding the canine over archwire of round cross section significantly increases the rate of space closure, degree of tipping and rotation.

3 . Sliding the canine by tieback retraction method gave rise to the highest mean value for the rate of space closure.

\section{REFERENCES}

1. Southard TE, Marshall SD, Grosland NM. Friction does not increase anchorage loading. Am J Orthod Dentofacial Orthop.2007; 131(3):412-414.

2. McLaughlin RP, Bennett JC, Trevisi HJ .Systemized orthodontic treatment mechanics .First edition, Mosby Company. 2001. Pp. 14, 13, 258, 111, 110, 252,254 
3. Wichelhaus A. Basics of sliding mechanics. 2007. P.1-35.

4. Bennett JC, McLaughlin RP. Orthodontic management of the dentition with the pre-adjusted appliance. Mosby company. 2002.

5. McLaughlin RP, Bennett JC.Bracket placement with preadjusted appliance. J Clin Orthod.1995; 29: 302-311.

6. Hain M, Dhopatkar A, Rock P.The effect of ligation method on friction in sliding mechanics. Am J Orthod Dentofacial Orthop. 2003; 123: 416-422.

7. Elsheikh MM, Godfreg K, Manosudprasit M, Viwattanatipa N.A pilot typodont study. Am J Orthod Dentofacial Orthop.2004; 7(2):107-116.

8. Eliades T, Bourauel C. Intraoral aging of orthodontic materials: the picture we miss and its clinical relevance. Am J Orthod Dentofacial Orthop. 2005; 127(4): 403-412.

9. Nightingale C, Jones SP.A clinical investigation of force delivary systems for orthodontic space closure. J Orthod. 2003; 30(3): 229-239.

10. Viazis AD. Atlas of advanced orthodontics: A guide to clinical efficiency . W.B.Saunders Company.1998.P.93.

11.Sureri MY, Turk T. Effectiveness of laceback ligatures on maxillary canine retraction. Angle Orthod. 2006; 76(6): 1010-1014.

12.Huffman DJ, Way DC. A clinical evaluation of tooth movement along archwires of two different sizes. Am J Orthod Dentofacial Orthop. 1983; 83(6): 453-459.

13.McDonald JL, Shofer FS, Chafari J. Effect of molar rotation on arch length. Clin Orthod Res. 2001;4(2):79.
14.Dixon V, Read MJF, O'Brien KD, Worthington HV, Mandall NA .A randomized clinical trial to compare three methods of orthodontic space closure . J Orthod. 2002; 29(1): 31-36.

15. Sonis AL. Comparison of NiTi coil springs vs elastics in canine retraction. J Clin Orthod. 1994; 28(5): 293-295.

16. Kula K, Kula T, Glaros A, Barlow J. Evaluation of printed and monitor displayed images taken with digital cameras and impoted into the dolphin imaging systems. Seminar Orthod. 2004; 10(3): 220-225.

17.Frank CA, Nikolai RJ. A comparative study of frictional resistance between orthodontic bracket and archwire. Am J Orthod.1980; 78(6): 593-609.

18. McLaughlin RP, Bennett JC .The transition from standard edgewise to preadjusted appliance system. J Clin Orthod. 1989; 23(3): 142-153.

19.Ziegler P, Ingervall B. A clinical study of maxillary canine retraction with a retraction spring and with sliding mechanics. Am J Orthod Dentofacial Orthop .1989;95(2):99-106.

20. Schumacher HA, Bourauel C, Drescher D. Frictional forces when rectangular guiding arches with varying edge bevel are employed. Am J Orthod Dentofacial Orthop. 1998; 59(3): 139-149.

21.Samules RH, Rudge SJ, Mair LH. A comparison of the space closure using a nickel-titanium spring and an elastic module: a clinical study. Am J Orthod Dentofacial Orthop. 1993; 106(5): 464467. 